\title{
浅谈“五学五问”课堂教学在初中历史教学中的实践应用 永州市第二十中学生态活力教育“五学五问”模式
}

何积伦

湖南省永州市第二十中学

DOI:10.32629/jief.v2i4.1269

[摘 要] 课堂教学中, 学生是教学活动所围绕的主体。学生主体作用的发挥, 是打开知识大门的钥匙, 是学生探求知识的发端, 是一切创新 的开始。没有问题, 就没有思维的动力。鉴于此, 为了进一步打造高效课堂, 促进教育教学质量的全面提高, 培养学生求问创新精神, 永州 市第二十中学实践了“五问五学”教学法。现就“五问五学”教学法的运行方法做了以下探讨。

[关键词] “五学五问”; 初中历史; 实践

中图分类号: G633.51 文献标识码：A

“五学五问” 包括自学提问、合学探问、导学拓问、练学省问、践学 行问五个方面, 本文将一一做以下论述。

\section{1 初中历史教学中的自学提问}

自学提问就是学生在自主学习的基础上, 发现问题、提出问题, 生 成原生态的问题, 充分发挥学生的主体能动性。历史知识大多以文字的 形式来进行阐述, 要求学生可以通过阅读大量的文字去获取有用的信息, 并透过历史现象, 能够理解历史事件发生的背景及其影响。这些都对学 生的阅读分析能力有着一定的要求, 需要学生能够提高文字的分析能力, 不断积累历史知识, 其历史成绩才会有所提高。教师应结合历史学科的 教学内容及其学科特色, 进行科学有效的安排自学材料和内容, 立足教 学发展全局, 不断优化教学设计, 以提高其有效性。学生作为教学活动 直接参与者, 能够感受到课堂质量提升带来的改变, 进行自学提问, 在 学习体验中得到优化与提升, 培养学生学习兴趣。例如在学习抗日战争时, 可设置一串问题: 1. 请同学们从日本、中国、国际环境等方面来思考一下 日本发动侵华战争的原因。2. 日本在侵华过程中犯下了哪些滔天罪行? 作 为中国人, 你又有作何感受? 3. 你知道哪些抗日时期的英雄和与他们有关 的故事吗? 4. 国共合作前后抗日战争发生了哪些变化? 5. 探究思考: 侵 华、抗战、胜利三者之间存在什么逻辑关系呢? 6 . 想一想: 結合鸦片战争 以来的史实, 分析抗战胜利的历史意义。这一组问题来源于教材又高于教 材, 问题之间有一定的梯度又体现了层次感, 能够激发学生进行思考, 在 自主学习的基础上, 不断提问让学生自我能力得到提升。

\section{2 初中历史教学中的合学探问}

合学探问就是以合作学习小组为单位, 在学生自学提问的基础上, 小组内对组员提出的问题, 互相之间进行合作探究, 互相启迪, 答疑解 惑, 充分发生学生的合作天性。初中历史学科的知识点繁多, 部分历史 事件存在着一定的争议性, 就连史学家对其的观点也不尽相同。那么, 在进行教学时, 教师可以选择部分观点明显, 可以用于历史事件, 来组 织学生进行探讨, 具体实施的话可以采取合作学习的方式。初中生思考 问题的出发角度始终有限, 看待事物也不尽全面, 单靠个人力量是很难 在历史事件的辩论中取得优异成绩的。这时就需要发挥集体学习的作用 了, 而合学探问就是实现这一教学效果的不错选择。具体而言, 教师需 要注意进行小组分配, 成员组合的力量尽量均衡, 不宜出现学习能力差 距千差万别的情况; 在进行材料准备时, 教师可以提供一些查阅资料的 途径以便学生参考, 鼓励学生积极进行探讨; 在进行探讨时, 需要教师 仔细听取学生的观点以及其运用的支撑材料, 便于结束之后对结果进行 点评。比如, 在进行《第一次国共合作的实现》教学中, 笔者设计了以 下五个问题: (1) 孙中山为什么要重新解释三民主义? (2) 新三民主义 “新” 在哪些方面 (从背景、内容、性质及作用方面分析) ? (3) 新三民主 义与三大政策的关系如何? (4) 新、旧三民主义有何联系和区别? (5) 新 三民主义为何会成为国共两党合作的政治基础? 通过精心设疑, 引发学 生思维, 让学生在积极思考和探讨中掌握基本史实和基本观点, 在思考 中分析和解决问题的能力得到培养。

\section{3 初中历史教学中的导学拓问}

导学拓问就是老师在学生自学提问、合学探问的基础上, 对学生提出 的问题, 小组里还没有解决的问题, 结合课标和老师预设的问题, 进行整 合, 拓宽掘深, 充分发挥教师的主导作用, 正在实现教学合一。在实际的 教学过程中, 对于学生来说, 有着一个具体的问题, 可以让学生在课堂上 有一个具体的学习内容, 让学生有一个问题, 可以围绕问题, 具体展开讨 论, 学生可以通过问题, 发现本节课的重点学习内容, 然后找到学习的方 向。例如在学习《原始农耕生活》这一课堂内容时, 教师要让学生了解到 我国原始农耕经济的主要情况, 了解中华文明处于起源阶段时原始农耕经 济的发展水平, 对于教师来说, 要给学生制定一个重点的问题, 比如在本 节课堂的学习过程中, 远古居民的生存方式有哪几种?

\section{4 初中历史教学中的练学省问}

练学省问就是在前面三个环节的基础上, 引导学生运用在自学、合 学、导学中获得的知识和技能进行当堂训练, 对训练中存在的问题进行 自我反省追问, 师生共同找出原因, 总结归纳, 提高学习效率。对于学 生来说, 多做练习, 可以加深学生对于历史的记忆, 让学生对于历史学 习, 有一个更为清楚的认识, 在传统的教学方式中, 教师会让学生巩固 知识, 传统的形式, 已经不再适应学生的综合发展了, 教师可以利用练 习过程, 巩固学生知识, 教师要对学生的练习方式进行优化, 教师要让 学生掌握一定的历史知识。用练习方式, 取代提问方式, 强调学生在有 效的时间内发挥学生的学习效果。练习让学生掌握技能, 学生可以思考, 降低了学生学习历史的难度, 提高了学生的学习效率, 让学生实现充分 的成长。

\section{5 初中历史教学中的践学行问}

践学行问就是学生将课堂里面通过自学、合学、导学、练学中学到 的知识, 掌握的方法, 形成的技能运用到课堂外面进行实践, 在实践中 边行边问。学生通过所学的历史, 形成良好的思维习惯与行为习惯。历 史的记忆是认识、了解自己在历史长河中所处的位置, 以及自己与全人 类之间的联系。每个人都是这一链条上的一环, 人类历史上的善与恶时 刻都影响着自身, 而人们的现状也将在未来影响自己的后代。无史之人 如同无根之树, 漠视自己的根和自己在历史长河中所处的位置, 就不会 有充分的自我意识和共同的社会意识。

总之, “五学五问” 课堂教学在初中历史教学中的实践应用, 能在教 学中充分激发学生学习历史的兴趣, 增强他们学习的主动性和积极性, 从而达到培养学习真正实现学史明志, 知史做人的目的。

\section{[参考文献]}

[1]何文奇.如何让信息化技术走进初中历史课堂教学 [J]. 新课 程,2020(37):6.

[2]杨茂同.初中历史创新教学策略浅谈[J].新课程,2020(37):152.

[3]田红彩. 初中历史项目式学习的价值及实施路径研究 [J]. 天津师 范大学学报(基础教育版),2020,21(04):53-57. 